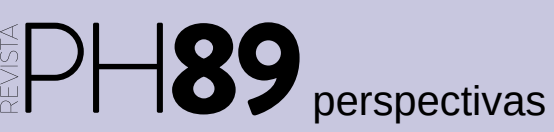

a debate Patrimonio, turismo y género. Estrategias para integrar la perspectiva de género en el patrimonio histórico

| coordinan Margarita M. Birriel Salcedo, Carmen Rísquez Cuenca

\title{
Patrimonio cultural y género: propuestas para el programa turístico Viaje al Tiempo de los Iberos
}

Ana B. Herranz Sánchez, Carmen Rueda Galán, Carmen Rísquez Cuenca | Instituto Universitario de Investigación en Arqueología Ibérica, Universidad de Jaén

URL de la contribución <www.iaph.es/revistaph/index.php/revistaph/article/view/3745>

Reformular el patrimonio en términos de capital cultural, como señalaba Néstor García Canclini siguiendo a Bordieu, le otorga la ventaja de "no presentarse como un conjunto de bienes estables y neutros, con valores y sentidos fijos sino como un proceso social, que se acumula, se renueva, y produce rendimientos en diversos sectores" (GARCÍA CANCLINI, 1999: 18). Esa reformulación, que dinamiza la noción de patrimonio al considerar sus usos sociales desde un punto de vista amplio y complejo, nos hace valorar, en nuestro caso desde el patrimonio arqueológico, la importancia que tiene el establecer vínculos entre este y la sociedad, atendiendo a la doble vertiente que supone, por una parte, la transferencia y difusión del conocimiento (procedente de la investigación) y, por otra, el uso y disfrute de ese patrimonio, donde el turismo ha cobrado un papel relevante en el marco del desarrollo económico de los territorios.

Ahora bien, cuando se han impulsado y puesto en marcha distintas estrategias para la activación de este patrimonio y las administraciones e instituciones han promovido y ejecutado los proyectos que han supuesto la puesta en valor de sitios arqueológicos, no se han tenido en cuenta las investigaciones que se vienen desarrollando (hace ya algunas décadas) desde la arqueología de género. Esto provoca, en definitiva, que se rompa la cadena que permite el tránsito desde las investigaciones a la sociedad, en este caso, al público que se interesa por los espacios arqueológicos. Este no es un tema baladí puesto que, al no incluir la perspectiva de género, lo que se transmite del pasado está sesgado, al no incorporar el conocimiento que se tiene sobre las mujeres y se convierte en una clara muestra de desigualdad. Trabajar por la igualdad de género es uno de nuestros compromisos $y$, en este sentido, también podemos utilizar el patrimo- nio arqueológico y el turismo como herramientas de gran utilidad para la transmisión de valores de igualdad.

En el marco de la I+D+i las investigaciones que se han emprendido bajo la perspectiva feminista y de género, a través de proyectos financiados por el Estado, las comunidades autónomas y otras instituciones, con el apoyo de la Universidad, han contribuido a que hoy tengamos un mejor conocimiento de las mujeres del pasado y de los roles que desempeñaron en sus respectivas sociedades. Nuestra propuesta se enmarca en uno de estos proyectos: GENDAR ${ }^{1}$.

Es precisamente en este contexto, y en concreto en relación a las sociedades iberas, donde planteamos anali-

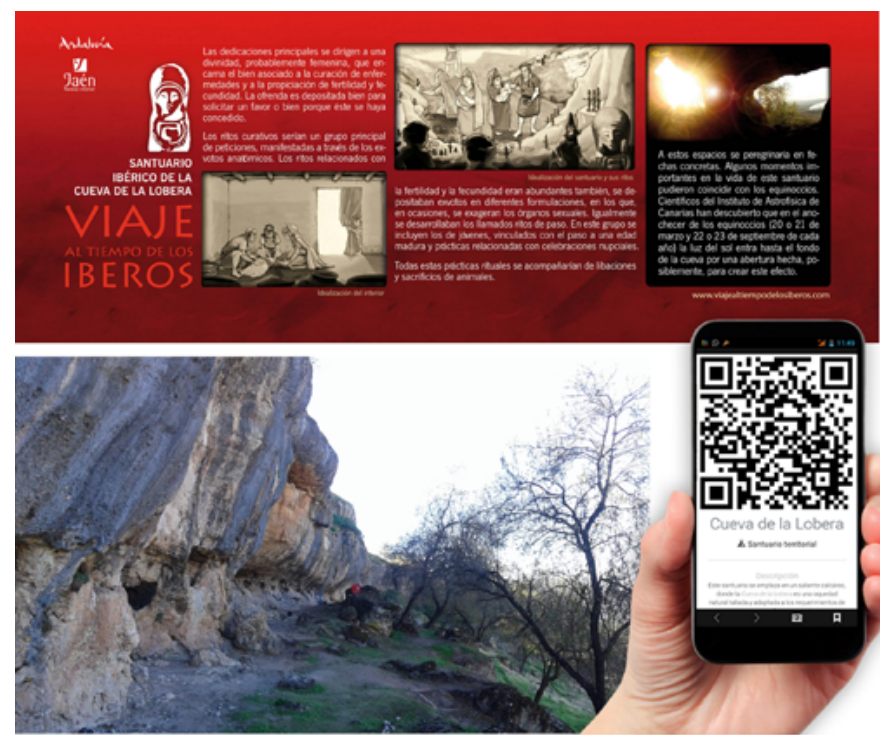

Vista del santuario de la Cueva de la Lobera de Castellar (Jaén) y panel interpretativo de este espacio arqueológico. Información que se está elaborando, accesible a través de códigos QR 
zar el Plan de desarrollo Turístico Viaje al Tiempo de los Iberos en la provincia de Jaén², con la intención de profundizar en las interpretaciones que se hacen de los distintos sitios arqueológicos visitables, preparándolos para comunicar y transmitir la información con un enfoque de género. En su momento, para su creación como producto turístico, la administración competente trabajó en una serie de actuaciones que quedaban englobadas en ocho programas, entre las que se incluían la adecuación interpretativa de sitios arqueológicos.

Un primer paso en nuestro trabajo ha consistido, precisamente, en evaluar si existe un sesgo de género en la interpretación que se ha llevado a cabo y en la información que se está ofreciendo al público. Para ello se han seleccionado cinco de los sitios arqueológicos de la ruta y que son exponentes de distintos escenarios, desde el oppidum (la ciudad), a los espacios de culto (santuarios) y los lugares de la muerte (necrópolis).

El resultado puso de manifiesto que tan sólo en uno de ellos, el santuario de la Cueva de la Lobera (en el que nosotras mismas hemos podido incidir en algunas fases del proceso, pero no en todas), se puede observar una mayor equidad en las representaciones de los paneles interpretativos (textos e imágenes) que visibilizan a los diferentes agentes sociales de las sociedades iberas. No sucedía lo mismo en el resto, donde se observa que la mayoría de los paneles no hacen referencia a grupos sociales (HERRANZ SÁNCHEZ, 2015). De igual forma, en la diagnosis que se ha realizado sobre el audiovisual, elaborado a modo de documental, se perciben varios sesgos significativos (HERRANZ SÁNCHEZ; GARCÍA LUQUE, 2016).

Nuestras propuestas se dirigen ahora a establecer las pautas indispensables para visibilizar a las mujeres y hacerlo en las distintas etapas de su vida, teniendo en cuenta también aquellas que han sido objeto de olvido en la investigación, como la infancia o la vejez. Aspecto fundamental, porque las personas que visitan esos lugares, de todas las edades, deben sentirse identificadas con ese pasado y reconocerse en esa memoria. Para ello, es significativo trasladar las investigaciones y las nuevas interpretaciones que se han generado desde la arqueología de género sobre estos sitios arqueológicos (RÍSQUEZ CUENCA, 2015; RÍSQUEZ CUENCA; GARCIA LUQUE, 2007; RÍSQUEZ CUENCA; RUEDA GALÁN, 2013; RUEDA GALÁN; RÍSQUEZ CUENCA, 2016; RUEDA GALÁN, 2013; ESTEBAN LÓPEZ; RÍSQUEZ CUENCA; RUEDA GALÁN, 2014). Es importante transferirlas con el uso de un lenguaje no sexista, que valore por igual las actividades desarrolladas por hombres y por mujeres en el pasado, empleando imágenes que integren a todos los agentes sociales y anulando las actitudes de sumisión, pasividad o debilidad que se han generado, a menudo, en las representaciones de las mujeres del pasado. Los nuevos contenidos que se están elaborando incluyen aspectos relativos a las actividades de las mujeres como la elaboración de los alimentos, el cuidado de las personas, la construcción de la comunidad y las tecnologías cotidianas, que no están contemplados actualmente en dicha ruta, lo que favorecerá el reconocimiento de las mujeres como sujetos activos, contribuyendo así a cambiar la mirada androcéntrica que caracteriza, también, al patrimonio arqueológico.

Estos trabajos, que están recién iniciados, llevan aparejados la incorporación de las nuevas presentaciones elaboradas, mediante la tecnología de códigos QR colocados en los soportes expositivos (paneles informativos) que permitirán un acceso inmediato a la información. 
a debate Patrimonio, turismo y género. Estrategias para integrar la perspectiva de género en el patrimonio histórico

| coordinan Margarita M. Birriel Salcedo, Carmen Rísquez Cuenca

\section{NOTAS}

1. Esta aportación se realiza en el marco del proyecto Recursos para la investigación de la arqueología de las mujeres y del género en España (GENDAR) HUM 1904, proyecto de excelencia de la Junta de Andalucía, convocatoria 2012, que es continuación de un proyecto anterior (GONZÁLEZ MARCÉN, 2012).

2. Promovido por la Diputación de Jaén y la Consejería de Turismo, con la colaboración de la Consejería de Cultura de la Junta de Andalucía, que partía de la idea inicial propuesta por el Instituto Universitario de Investigación en Arqueología Ibérica de la Universidad de Jaén, del que formamos parte.

\section{BIBLIOGRAFÍA}

- eSTEBAN LÓPEZ, C.; RÍSQUez CUENCA, C.; RUEDA GALÁN, C. (2014): Una hierofanía solar en el santuario ibérico de Castellar (Jaén). Archivo Español de Arqueología, n. ${ }^{\circ} 87$, 2014, pp. 91-107

- GARCía CANCLINI, N. (1999) Los usos sociales del patrimonio cultural. En AGUILAR CRIADO, E. (ed.) Patrimonio etnológico. Nuevas perspectivas de estudio. Sevilla: Junta de Andalucía. Consejería de Cultura. Instituto Andaluz del Patrimonio Histórico y Editorial Comares, 1999, pp. 16-33 (Cuadernos $\mathrm{PH} ; 10$ )

- GONZÁlez MARCÉN, P. (ed.) (2012) Los trabajos de las mujeres y el lenguaje de los objetos: renovación de las reconstrucciones históricas y recuperación de la cultura material femenina como herramientas de transmisión de valores [en línea]. Madrid: Ministerio de Sanidad, Servicios Sociales e Igualdad. Secretaría de Estado de Servicios Sociales e Igualdad. Dirección General para la Igualdad de Oportunidades. Instituto de la Mujer, 2012 <http://www. inmujer.gob.es/areasTematicas/estudios/estudioslinea2012/ docs/los_trabajos_mujeres_lenguaje_objetos.pdf> [Consulta: 09/02/2016]

- HERRANZ SÁNCHEZ, A. (2015) Gender perspective in Heritage Interpretation. A case of study: A Journey to the Time of the Iberians. En Abstracts Book of the 2015 Doctoral Conference for Young Researchers at the University of Jaén. Jaén: Universidad de Jaén, 2015, p. 4

- HERRANZ SÁNCHEZ, A.; GARCÍA LUQUE, M. ${ }^{a}$ A. (2016, en prensa) ¿Educación patrimonial con perspectiva de género?: análisis del viaje al tiempo de los íberos (Jaén). En XXVII Simposio de Didáctica de las Ciencias Sociales. Asociación Universitaria del Profesorado de Didáctica de las Ciencias Sociales (AUPDCS), 2016 en prensa

- RISQUEZ CUENCA, C.; GARCíA LUQUE, M. ${ }^{a}$ A. (2007) Mujeres en el origen de la aristocracia ibera: una lectura desde la muerte. Complutum, n. ${ }^{\circ} 18,2007$, pp. 263-270

- RÍSQUEZ CUENCA, C.; RUEDA GALÁN, C. (ed.) (2013) Santuarios Iberos: territorio, ritualidad y memoria. Actas del Congreso El santuario de La Cueva de la Lobera de Castellar. 1912-2012 [en línea]. Jaén: Asociación para el desarrollo rural de la Comarca de El Condado, 2013 <https://www.academia. edu/5818794/Santuarios_Iberos_territorio_ritualidad_y memoria._Actas_del_Congreso_El_santuario_de_la_Cueva_ de_la_Lobera_de_C̄astellar_Ja\%C3\%A9n_._1912-2012> [Consulta: 09/02/2016]

- Rísquez CUENCA, C. (2015) La arqueología ibérica y los estudios de género en Andalucía: avances y desafíos. Menga: Revista de Prehistoria de Andalucía, Dossier sobre Feminismo, Mujeres y Arqueología. coordinado por M. Sánchez y E. Alarcón, n. ${ }^{\circ}$ 6, 2015, pp. 61-91

- RUEDA GALÁN, C.; RíSQUez CUENCA, C. (2016) Transformaciones religiosas en los santuarios iberos del Alto Guadalquivir: los cambios en la imagen votiva femenina (siglos IV-I a. C.). En RUSSO, A.; GUARNERI, F. (ed.) Santuari Mediterranei tra Oriente e Occidente. Interazioni e contatti culturali. Roma: Soprintendenza per I beni archeologici dell'Etruria Meridionale, Ministero dei Beni e delle Attività Culturali e del Turismo, 2016, pp. 389-392

- RUEDA GALÁN, C. (2013) New views on the analysis of dress, ritual and prestige in Iberian sanctuaries: preliminary results. En ALFARO, C.; ORTIZ, J.; MARTÍNEZ, M. J. Luxury and dress. Political power and appearance in the Roman Empire and its provinces. Valencia: Universitat de València, 2013, pp. 31-50 